\title{
EL MUNDO FEMENINO EN ALGUNOS CUENTOS DE RIMA DE VALLBONA
}

\author{
POR \\ CIDA S. CHASE \\ Okiahoma State University
}

Rima de Vallbona se ha dado a conocer con dos buenas novelas: Noche en vela (1968), que logró una segunda edición en 1982, y Las sombras que perseguimos (1983). Sin embargo, ya desde los años sesenta ella se había iniciado en la narrativa con La salamandra rosada, una bella colección de cuentos que tuvo guardada hasta su publicación en $1979^{1}$. Otras colecciones de cuentos que han sido muy bien recibidas en el mundo de las letras son Polvo del camino (1971), Mujeres y agonias (1982) y Baraja de soledades (1983), la cual contiene algunas selecciones ya incluidas en Mujeres y agonías. Actualmente, la escritora tiene preparada otra colección, El hondón de las sorpresas, que pronto encontrará el camino de la imprenta. Muchos de los cuentos que forman parte de este último libro ya han aparecido publicados independientemente en revistas literarias hispanoamericanas, estadounidenses y europeas ${ }^{2}$. Este ha sido el caso de la mayor parte de las narraciones cortas de Vallbona.

${ }^{1}$ Así me lo explicó la escritora en una carta del 25 de marzo de 1985.

2 Entre los cuentos que figuran en esta colección están los siguientes: «Más allá de la carne», Foro Literario (Uruguay), 3 (primer semestre 1978), pp. 15-17. También apareció en Letras Femeninas (USA), 1 (Spring 1978), pp. 105-108. En Francia se publicó con el título de "Bien au-delà de la chair», Fer de Lance, 103 (juillet-septembre 1979), pp. 14-17. «El hondón de las sorpresas», Revista ChicanoRiqueña (USA), 4 (Fall-Winter 1980), pp. 35-37. En Francia se publicó con el título «Le Tréfonds de la surprise», Fer de Lance, 111-112 (juillet-décembre 1980), 12-14. «Alma-en-pena», Revista Chicano-Riqueña, 3-4 (Fall-Winter 1983), pp. 122-126. Este cuento ya se había publicado en Francia, «Âme en peine», Fer de Lance, 115-116 (juillet-septembre 1981), pp. 33-37. «Desde aquí», Garcín-Libro de Cultura (Uruguay), 3 (noviembre 1981); pp. 56-59. «El muro», La Costa de Oro (Uruguay), 21 (febrero 1982), pp. 14-15. "Tierra de secano», Letras Femeninas (USA), 1 (Spring 1983), pp. 80-83. «Iniciación», Cuaderno Literario Azor (España), 37 (enero-marzo 1983), pp. 49-50. 
Los cuentos de Vallbona llaman la atención porque su discurso no sólo acusa un gran dominio de la lengua, sino que aparece permeado de gran sinceridad. Aunque para la escritora no hay ningún tema vedado, en sus textos predominan las realidades oprimentes de gran número de mujeres y niños desamparados. A través de sus narraciones ella logra profundizar en situaciones de contexto universal, en situaciones en que el pathos humano se hace penetrante. Su discurso termina agitando el ánimo del lector y promoviendo sentimientos de dolor. Vallbona parece poseer esa cualidad intangible denominada empatía, cualidad algo rara en estos días de mecanización galopante. Como bien lo expresa Lilia Ramos, «Rima plantea conflictos fundamentales del ser humano y formula interrogaciones dolorosas. En todas (sus obras) lo hace embargada por la angustia metafísica» ${ }^{3}$.

El presente trabajo se dedicará a examinar ciertos aspectos del mundo femenino en los cuentos de Vallbona. Para lograr este propósito se utilizarán cuatro selecciones de Polvo del camino, otras tantas de Mujeres y agonías y dos textos seleccionados de sus múltiples publicaciones en revistas literarias: «Alma-en-pena» y «Los males venideros» ${ }^{4}$. Polvo del camino constituye una colección de diez cuentos y un epílogo. Mediante un discurso claro con algunos toques alucinantes, pero en cuya enunciación prevalece la oralidad, la escritora desarrolla temas que van de la discriminación racial al incesto, pasando por la necesidad de evadir una realidad insoportable, hasta llegar a querer desentrañar los conceptos filosóficos de la soledad y del dolor.

Uno de los primeros cuentos que impresiona grandemente es «Caña hueca». E1 texto deja entrever su espíritu en el epígrafe, proveniente de la Imitación de Cristo, de Kempis, capítulo VII: «No confíes ni te apoyes sobre la caña hueca ${ }^{5}$, porque toda carne es heno y toda su gloria caerá como la flor del heno.» El discurso establece una antítesis entre dos personajes femeninos: Dorita, que vive entregada al goce de los sentidos, y Caridad, la maestra solterona del pueblo. Ambas viven en un pueblo donde la vida privada de cada individuo es patrimonio de todos y constantemente es sometida a censura. «El qué dirán», o mejor decir, «el qué dicen», es una constante en el discurso y constituye su elemento dinámico.

${ }^{3}$ Rima de Vallbona, Polvo del camino (San José, Costa Rica: Autores Unidos, 1971), Preámbulo, p. 8.

${ }_{4}^{4}$ Véase nota 2. «Los males venideros» apareció en Alba de América, 2-3 (1984), pp. 221-227.

${ }^{5}$ Mi texto de Kempis publicado en Turnhout (Bélgica): Establecimientos Brepols, S. A., 1956, utiliza el adjetivo «vacía» en lugar de «hueca», p. 179. 
La voz que narra comienza con la presentación de Dorita, a quien se ve como la personalización del pecado:

También cuentan de Dorita, la costurera que convierte su casucha temblona en una estremecida orgía en sus repetidas noches de amor. De Dorita hablan todos, hasta las beatas oscuras que van haldeando a la misa de cinco. Con el ardor de su cuerpo, Dorita en realidad ocupa el pueblo entero, desde la Sacristía hasta la barraca del verdulero: Dorita es un contoneo armonioso que lleva tras sí la mirada ávida de los hombres; Dorita es una voz melodiosa y sensual que perturba a los adolescentes hasta producirles dolor en la ingle (p. 55) ${ }^{6}$.

Toda la introducción del texto se dedica a Dorita, quien siempre va acompañada de un aura de murmuración y deshonra. Pero en ese pueblo, donde «en la oscuridad se adivinan siempre ojos rutilantes al acecho de la víctima entre los matorrales del camino» (p. 56), también hablan de la maestra del pueblo:

E1 pueblo murmura de la soledad que se va acumulando en la casa de la señorita Caridad; afirman que esa soledad ocupa hoy todos sus rincones como un ser ancho y concreto, ha salido a la puerta y ha espantado a los pocos que de cuando en cuanto venían a ver a la maestra. Esta trae sus ropas y sus carnes tan saturadas de soledad, que despide un raro olor a gardenia marchita; a veces más bien a ciprés seco; ya los ojos se le han puesto ausentes, las manos ásperas y la voz repulsiva, sobre todo cuando regaña a los niños en la clase. Caridad Refunfuños la llaman mientras ríen con una risa que ignora totalmente el dolor de la soledad, los desgarros que ésta abre en el alma (p. 57).

En la presentación de la maestra, el término «soledad» continúa repitiéndose hasta convertirse en un signo que apunta al matiz filosófico del discurso. La sombra de la soledad se ve en el lenguaje metafórico de la narración y se convierte en un aspecto predominante del cuento. La voz de Caridad aparece «gangosa y carcomida de soledad» (p. 56); la maestra «es un pozo de soledad», «hay soledad en su gesto», «soledad en su ir y venir a la escuela» y hay sabor de soledad en sus comidas (p. 57). E1 narrador establece un paralelismo ideológico entre los conceptos soledad y monotonía. Este último aspecto se manifiesta también estilísticamente mediante la repetición. Se dice cómo desde hace años la maestra «oye, oye y oye el farfullar de la chiquillada repitiendo, repitiendo» (p. 56), y desde

\footnotetext{
- Véase nota 3. Todas las citas provenientes de Polvo del camino se tomarán de esta edición.
} 
tiempos inmemoriales ella viene a clase sin faltar un día, "así llueva o truene», «lunes, martes, miércoles, jueves, viernes y sábado... lunes, martes, miércoles, jueves, viernes y sábado» (pp. 56-57).

Ese vivir sin vivir cambia para la maestra cuando aparece en la narrativa un tercer personaje femenino, la forastera Juliana Alcalde, que decide ocupar una habitación en la casa vacía de Caridad. Es el momento en que el pueblo, convertido en una especie de Argos, abre sus múltiples ojos y hace correr la voz de que la relación entre Caridad y la forastera es pecaminosa. Sin embargo, el verdadero patetismo del discurso surge cuando Dorita logra conquistar a Juliana Alcalde y Caridad vuelve a su estado inicial de soledad. El espíritu de denuncia en el discurso aparece implícito en la conducta de los actantes, miembros de una comunidad donde «hasta los animales son malvados; se parecen mucho a sus dueños» (p. 56). Es interesante notar que el único individuo sin tacha en ese pueblo es Chumico el Tonto, cuyas pocas luces le impiden «apoyarse sobre la caña hueca» y así él puede seguir fácilmente los pasos de Cristo.

«Con los muertos al cinto» lleva también un epígrafe de Kempis, que constituye un enunciado valioso en el texto: "Muchas veces no sentimos cuán ciegos estamos en el alma.» Se trata aquí de la violación de una niña que se desplaza en la noche «tanteando el aire con su bastoncillo de poró» (p. 69). Ya en la primera frase se intuye el ambiente rural del discurso y su situación local en Costa Rica, donde el poró es uno de los elementos más comunes de la flora silvestre. Sin embargo, este cuento interesa porque no sólo alcanza universalidad en el asunto y la técnica, sino que presenta evidencias de la intertextualidad de la escritora. La noche del cuento es toda una metáfora extendida, una bestia constituida de lujuria:

La noche toda negra, con mil ojos, mira a la niña. La noche inmensa, ávida, con sus mil ojos lúbricos la está espiando. La noche tiene brazos y tiene piernas; y clavado en medio, un deseo animal que se estremece en su sexo (p. 69).

La noche cobra una extraña forma humana, pero la niña no logra descubrirle su contorno con el bastoncillo al aire. La noche tiene ahora un trotar de fauno que la va persiguiendo con hambre de sexo por el camino interminable.

La niña ciega quiere correr, pero la noche le va tendiendo trampas a su paso. Sus piececitos descalzos se enredan, tropiezan... cae al suelo desolada y sobre ella se abalanza la noche hecha deseo libidinoso (p. 70).

Los párrafos citados traen a la mente el hermoso texto lorquiano «Preciosa y el aire», donde la niña se ve envuelta en una noche oscura y si- 
lenciosa o, como enuncia el poeta, en un «silencio sin estrellas» ${ }^{7}$ y una «noche llena de peces». En lugar de un bastón, Preciosa 1leva una pandereta, cuyo sonido rompe el silencio poniendo tal vez alerta la bestia lujuriosa del poema: «el viento que nunca duerme», imagen que se transpone en el texto de Vallbona como un monstruo con sus «mil ojos lúbricos». E1 viento se presenta en el poema como «San Cristobalón desnudo, / lleno de lenguas celestes», / «El viento-hombrón» que «la persigue»/ «con una espada caliente». Estas imágenes aterradoras y profundamente eróticas se perciben en el discurso de Vallbona en la «extraña forma humana» que toma la noche, que aparece consumida por «un deseo animal que se estremece en su sexo» y que «va persiguiendo» a la niña «con hambre de sexo». Desafortunadamente, la niña de «Con los muertos al cinto» no tiene oportunidad de contar «1lorando» «su aventura» a ninguna gente en medio de la noche y cae víctima de la maldad que puebla las sombras.

La voz que narra logra despertar un pathos infinito por la niña ciega, acentuando la fragilidad de la pequeña mediante el uso de diminutivos como «bastoncillo» y «piececitos». Asimismo establece una antítesis muy eficaz entre el «trotar de fauno» del monstruo libidinoso y «los piececitos descalzos» de la niña, que «se enredan, tropiezan...». Se hace evidente en el discurso que quien se ha disfrazado de noche para cometer el crimen es Chepe, el guitarrista, quien lleva la noche «metida en la médula dal alma» y cuya guitarra «tiene en cada ritmo una virginidad rota» ${ }^{8}$. E1 patetismo de la narrativa crece aún más cuando se acusa a la niña de haber dado muerte a la criatura que se produce de la violación. La niña no alcanza a comprender lo que sucede porque su ceguera sobrepasa el plano físico y ella no sabe cuán ciega está en el alma.

«Con los muertos al cinto» es probablemente la narrativa más lograda de Polvo del camino, por sus figuras alucinantes y por su estructura. La evocación del texto de García Lorca es también un hallazgo feliz, porque la escritora logra una permutación muy acertada. Después de todo, parte de la destreza de un escritor es lograr establecer una similitud, una igualdad de dos discursos de naturaleza distinta ${ }^{9}$.

«La cucaña del deseo» interesa no sólo por el matiz filosófico del discurso, sino porque ya en esta narración se percibe el ambiente onírico que va a prevalecer en los cuentos de Mujeres y agonías. Según Lilia Ramos, este cuento constituye «Un vistazo de uno de los barrios josefinos más repletos de historia» y es «Un raro caso de sadomasoquismo devora-

${ }^{7}$ Federico García Lorca, Obras completas (Madrid: Aguilar, S. A. de Ediciones, 1968), pp. 426-428. Todas las citas del poema lorquiano se tomarán de esta edición.

${ }^{8}$ R. de Vallbona. Polvo del camino, p. 70.

9 Julia Kristeva, Le texte du roman (Paris: Mouton \& Co., 1970), p. 49. 
dor» ${ }^{10}$. En verdad, la toponimia revela la situación local del discurso. El drama se desarrolla en una "casucha de adobes en la avenida de Las Damas» (p. 93). Y el narrador denuncia los cambios drásticos que ha sufrido la ciudad de San José:

Me duele ver que pedazo a pedazo van despojando a mi ciudad de lo más auténtico suyo: ayer gran señora antañona, hoy prostituida por remedos de estilos a la moda, mal diseñados y peor construidos. Una ciudad impersonal: ha perdido ya ventanales de rejas, balcones románticos que miraban coquetuelos a la Avenida Central, y su inocente antigüedad decorosa (p. 93).

El meollo del discurso trata de la neurosis de la tía Anita, quien hizo de su hermano la víctima inmediata y sin escrúpulo alguno le robó la vida, su tiempo terrenal. El epígrafe que acompaña el texto proviene de Azorín y constituye un enunciado que alude a la preocupación del tiempo que poseía el tío Paco, que era relojero. El narrador indica cómo este personaje «Pasaba su vida tras el ventanal sucio montando relojes, puliendo y ajustando piececitas, regulando el tiempo. -iTan escurridizo y poco controlable, el condenado!» (pp. 93-94).

Desde muy temprano, el narrador establece un contraste entre la muljer neurótica, egoísta y el paciente relojero. Así dice:

Mi tía Anita, jamona y sonrosada, dormía plácidamente en la ancha cama matrimonial de sus padres, en la habitación más clara, aireada y bonita de la lóbrega casucha (p. 94).

Mi pobre tío Paco dormía en la trastienda en un camastro destartalado y de cuya dureza se protegía con un flaco jergón todo comido de remiendos (p. 95).

La tía Anita se alarma cuando el relojero habla de casarse con la rubia Katia, de quien está enamorado. Expresa que es necesario economizar para la vejez. La mujer tampoco puede tolerar la idea de que un Gómez Laredo se case con la hija de un turco afilador (p. 95). El tío Paco permanece solo con sus sueños mientras se dedica a sus relojes, y así comienza un eterno monólogo filosófico que el joven narrador no comprende:

¿Y si Dios me estuviera viendo ya completo, total, definitivo... mientras yo me empeño en quedar solamente esbozado? ¿Dios se habrá

${ }^{10}$ R. de Vallbona, Polvo del camino, Preámbulo, p. 10. 
sentido alguna vez insatisfecho del remate que dio a ciertas criaturas suyas? Muerto, ¿dónde y cómo realizar con plenitud y autenticidad la vida? Si yo mismo no la realizo ahora, mientras la sangre corre en mis venas, ¿quién, quién la realizará por mí después? (p. 96).

E1 enunciado empieza a tener ecos lejanísimos de Borges, ecos que luego se convierten en verdaderas lecciones de «Las ruinas circulares». El narrador logra completar la vida del tío Paco, soñándolo satisfecho con la esposa rubia y rodeado de chiquillos. En el sueño le oye decir:

Hijo, soy feliz, muy feliz. Ya lo ves, Katia era mi gran ilusión... hoy se realiza al fin... gracias a vos, que me permitís cumplirlo en tu sueño de la noche (p. 100).

Así alcanza el personaje la cumbre de la cucaña. El personaje femenino, personificación del egoísmo y la neurosis, no escapa la ira de la justicia poética: «Tía Anita murió primero, un poco anémica, otro poco desmemoriada y con baile de San Vito» (p. 99).

«Balada de un sueño» presenta aún una realidad más onírica que la anterior. La protagonista es muy característica de los personajes femeninos de Vallbona en narraciones posteriores. El mundo de Silvia se circunscribe a desempeñar el papel de esposa y madre. Por eso cuando la infidelidad del marido destruye ese mundo, Silvia busca liberarse a través del camino de la evasión. La voz narradora enuncia el efecto que la aparición de «la otra» tiene en la esposa en los siguientes términos:

¿Por qué crece el sillón de Silvia en esos momentos? Desproporcionada aumenta y la abarca a ella en sus muelles, armazón, tapizado, como un gigantesco pulpo... 1a envuelve toda... la comprende en su ser de sillón. Allí en el fondo sin fondo del sillón queda Silvia sin asidero en la realidad, buscándose a sí misma en un aire raro sin esencia (p. 103).

Silvia se siente físicamente empequeñecida y le es difícil reconocer la realidad que le rodea. Así se manifiestan los primeros síntomas de evasión. Su única realidad, la de pasear, comprar, charlar, realizar los quehaceres de la casa, cuidar de los niños, se le va haciendo gradualmente más vacía, más ajena, más lejana. El personaje se ve obligado a buscar la realidad deseada más allá de la realidad, en el mundo de los sueños. En los sueños de Silvia, el lector encuentra de nuevo lecciones borgianas porque el personaje logra forjar un amante castísimo, un poeta que acude a ella y satisface su necesidad de cariño: 
En la feria del sueño el desconocido llega, toma a Silvia de la mano y se la lleva a un pequeño café. Sin decir nada la hace sentarse frente a él y desde su silla la mira tiernamente. Ella es feliz acariciada por esos ojos tan llenos de alma. No quiere hacer preguntas... que el tiempo pase indefinidamente en ese silencio saturado de palabras únicas... que el sueño no termine jamás (p. 108).

En los sueños iniciales se hace evidente el hambre de afecto de la mujer. Asimismo, eî lector percibe que el personaje aún mantiene lazos con la realidad, porque hace notar que su amante «no bebe nada; tampoco come; sólo la mira» (p. 108). En otras palabras: su creación no es todavía un hombre de carne y hueso. Es más bien un ser etéreo y hecho de sustancia espiritual. Sin embargo, cuando los sueños ocurren ya en pleno día en medio de sus labores manuales y el hombre se manifiesta materializado, la realidad circundante de la mujer empieza de lleno a fragmentarse:

«¡Qué bella labor, señora! ¡Si es bordado de ángeles!» Esa voz con palabras que parecian recién estrenadas... esa voz que decía con eco lejano de sueño «Te esperaba. Te llevo esperando una eternidad, Silvia.» ¿Esa voz, esas manos y el corazón que palpitaba precipitadamente en la garganta y repercutía en el cerebro! Silvia no se atrevía a mirar a su interlocutor... era él, sólo él quien le hablaba en esos momentos (p. 110).

Silvia termina con enajenarse por completo. Como Horacio en Rayuela y Andrés en Coronación, esta mujer encuentra consuelo sumiéndose en el mundo de la locura y la irrealidad. Este es un universo personal donde no existen ni el dolor ni la humillación. Vallbona magnifica aquí el concepto de «dolor», término que se convierte en un signo del padecer humano. Este vocablo se repite un nutrido número de veces en el discurso (p. 113).

La toponimia de esta narración indica su situación local, San José. A Silvia se le conduce al Asilo Chapuí, pasando por el paseo Colón. A la llegada, ella ve «dos hombres observándola de reojo... los dos leones de piedra al final del camino de palmeras... la casa de las palmeras, risueña, piadosa imagen infantil del manicomio...» (p. 114).

El personaje de Silvia tiene mucho en común con la desafortunada protagonista de «E1 monstruo de las cosas», cuento que habrá de discutirse más adelante en este trabajo. En ambos discursos se hace aparente la angustia anímica de los personajes a través de sensaciones auditivas y gritos interiores. Cuando Silvia se encuentra en su cámara de enferma en trance de percibir múltiples ruidos de llaves y de puertas que se abren y se cierran, el narrador informa: 
De pronto un grito desgarra el aire, traspasa agudo las paredes y ella lo siente agitarse tan dentro de sí, que no sabe ya si es suyo, si ella es fibra de grito. Ser grito, ser nada (p. 114).

La evasión final de Silvia es la muerte, otro concepto clave en el discurso. Cuando ocurre la muerte de Silvia muere también el amante creado con sustancia de sueños. Sin embargo, la escritora le da un remate novedoso a su narrativa:

Con formularias palabras de condolencia los periódicos de la mañana anunciaban en la página necrológica la muerte de la señora Silvia Alcor de Palacios, esposa del eminente cafetalero don Víctor Palacios Dávila. Una esquela en la misma página hablaba brevemente del poeta Miguel Angel Gómez Lesak, muerto en la sala de operaciones, después de una larga dolencia (p. 116).

La realidad de la existencia del poeta se hace tangible sólo a través del anuncio de su muerte. ¿Y el lector? El lector queda azorado.

Mujeres y agonias constituye una colección de trece cuentos de los cuales emana una conmovedora sinceridad de confesonario. Como en Polvo del camino, los temas se presentan desde el interior de los personajes, y como la escritora muestra gran habilidad en saltar de experiencia en experiencia, el discurso aparece lleno de vitalidad. La oralidad del discurso se hace también presente en estos cuentos.

El texto que inicia esta colección se titula «Penélope en sus bodas de plata», y lleva una dedicatoria muy significativa: «A la mujer que se ha descoyuntado de la sociedad farisea.» A través del punto de vista de un hijo, el lector conoce los sacrificios que una mujer ha realizado durante veinuicinco años de matrimonio y vida doméstica:

... mamá no tiene canas, pero en sus ojos parece que llevara una lápida que le sepultara la vida por dentro. En las mañanas, al levantarse, tiene en la tez una rara humedad, como si el rocío de la noche le regara los leves surcos que ya comienzan a delinearse alrededor de stis ojos. Ni una cana. El cabello limpio, reluciente, castaño rojizo, recogido en un elegante moño. Mientras no habla de todo eso cotidiano («traé la ensalada de papas, Jacinta»), se diría una figura imperial salida de un lienzo de museo. Pero al ir pronunciando las cosas de cada día con su voz simple («el pozol salió sabroso»), con el canturreo de su pueblo, su piel se vuelve de materia vil, despreciable; dan ganas de amordazarla y esconderla en un rincón; dan ganas de taparse los oídos para seguir viéndola imperial y bella. ¿Por qué diantres no sale de su plátano, repollo, picadillo, verdolagas...? iAy, mamá, mamá! ¡Cuántas 
vergüenzas he pasado cuando vienen mis amigos y ella que si los tomates... 11

La realidad aniquiladora de este ser humano está representada en el discurso mediante nombres de comidas, olores a fritangas que emanan de la cocina $y$, en ocasiones, a través del temor a las penas del infierno. E1 hijo, aunque a veces vislumbra en su madre ansias de «un paraíso insospechado» (p. 14), no comprende el mundo oprimente del personaje que lleva a cuestas el papel que le ha asignado la sociedad. La paciencia y esperanza de esta mujer se universalizan relacionándolas íntimamente con el mito de Penélope:

Para ella, el sillón junto a la ventana y las dos agujas que no se cansan tejiendo, tejiendo, tejiendo, siempre tejiendo. Espera algo. Yo sé que espera algo. Cada movimiento de su aguja, tápido, nervioso, dice que espera algo. ¿Pero lleva tanto esperando! ¿Y qué ha tejido durante ese largo tiempo? Debe tener un cuarto lleno de colchas, escarpines, cotoncitas, almohadones, suéters, gorros, bufandas (p. 13).

Pero el personaje de este cuento va más allá del mito clásico porque no sólo teje para pasar el tiempo y mostrar su paciencia infinita. Mediante esta actividad, la mujer está forjando su propio destino y preparándose para alcanzar su paraíso personal. En cada prenda que diseña ella ve un patrón para su vida futura. Mircea Eliade explica claramente este proceso cuando expresa que «tejer no es meramente predestinar (antropológicamente) y unir realidades distintas (cosmológicamente), sino que es crear, forjar algo de sustancia propia como la araña cuando teje su tela» ${ }^{12}$.

Mientras el personaje se crea el futuro, la voz que narra gradualmente implica el ámbito de monotonía y abnegación en que vive la madre, representándolo simbólicamente en la «lana blanca, lana blanca, lana blanca» (p. 15), que continuamente utiliza para sus diseños. A través de un constante juego de antítesis entre la realidad cotidiana, las ansias de liberación, el infierno y el paraíso a que aspira el personaje, el cuento llega a su clímax la noche de la celebración de las bodas de plata. La madre, majestuosamente envuelta en ese gesto imperial que su hijo había perci-

${ }^{11}$ Rima de Vallbona, Mujeres y agonías (Houston: Arte Público Press, 1982), p. 15. Todas las citas provenientes de Mujeres y agonias se tomarán de esta edición.

${ }_{12}$ Patterns in Comparative Religion, trad. de Rosemary Sheed (Cleveland: World Publishing, 1985), pp. 181-182. He aquí la cita original: «to weave is not merely to predestine (anthropologically), and to join together differing realities (cosmologically) but also to create, to make something of one's own substance as the spider does in spinning its web». 
bido, anuncia ante los invitados que está conscientemente preparada para dar a su vida el rumbo que desea y realizar sus propias ambiciones. Pacientemente distribuye entre todos la infinidad de prendas que hacía años venía tejiendo. Los invitados salieron «locamente disfrazados de lana blanca, blanca, blanca» (p. 20). El personaje logra así sobreponerse a la frustración de una existencia que la estaba obligando a ser distinta de lo que ella íntimamente quería ser.

Otro cuento que desarrolla un tema semejante es «Parábola del Edén imposible». En él se presenta también un contraste entre la realidad que se vive y la realidad deseada. El ámbito circundante se refleja en la enumeración de tareas domésticas presentadas en palabras compuestas mediante guiones como: «su limpia-casa, barre-suelos, cambia-pañales, lavaplatos, marido-en-la-cama y final-de-día-vacía-rota-toda-por-dentro» (p. 21). Es un mundo de «oscuridad-inflerno-sin-estrella» (p. 22) y se relaciona constantemente con el quehacer o rito necesario de Sísifo (pp. 22-23). La realidad a que el personaje femenino aspira se manifiesta como «una profunda estrella azul» (p. 21) que ella ha notado en el ojo derecho de las mujeres que viven satisfechas con la vida que se han forjado. Esta realidad es como un «paraíso soñado» (p. 22), una realidad onírica inalcanzable. Así relata la voz que narra los esfuerzos del personaje por alcanzar esa dimensión desconocida:

Cuando al fin logró construir la nave de pétalos nuevos de rosa —ifue también en sueños?-, en medio de las aguas se disolvió... sólo dejó círculos concéntricos y la angustia de tener que nadar a la orilla, la única que conocía, para salvarse... volver al rito de Sísifo, continuar vacía, incompleta.

Por eso cuando apareció él, todo cara, cuerpo, carne, músculo y hueso, y le dio la mano en aquella fiesta aburrida de diálogos que ensanchaban las distancias entre las personas, ella supo que él sería el único que podría construir la nave, izar las velas rumbo al paraíso-plenitud, y llegar (p. 23).

Como puede verse, la mujer se acerca al paraíso deseado de un modo intuitivo y sensual; trata de encontrar su propia existencia sin darse el trabajo de forjarla por sí misma. Además, ansía alcanzar sus sueños de una manera tradicional, a través del amor, y sobre todo precisa de la ingeniosidad masculina para poder salir de la realidad que detesta. Como no logra encontrar la salvación por sí misma como lo hiciera el personaje de «Penélope en sus bodas de plata», fracasa en su empresa y se ve obligada a volver al quehacer de Sísifo. 
«El monstruo de las cosas» presenta también un personaje femenino que opera a un nivel elemental de la actividad humana. Su universo, como el de Silvia en «Balada de un sueño», se limita a un estrecho ámbito doméstico, el cual se identifica mediante enumeraciones caóticas, ruidos y opresiones que emanan de la casa:

Libros, cuadros, mesas, sillas, estanterías, adornos, alfombras, matas, cuchillos, televisores, platos, tazas, radios, ruidos, lavadoras, risas, golpes, aspiradoras, chillidos, silbatos... No hay ya espacio en esta casa atiborrada hasta el último rincón de cacharros y bullicio. Ya no sé ni dónde descansar mi cuerpo ni reposar mi espíritu, estrujados por el monstruo de las cosas (p. 47).

El caos exterior, visto como un reflejo de la angustia interior del personaje, se pone en evidencia constantemente en forma auditiva. Los sonidos salen de la televisión, la radio, la cocina, los miembros de la familia y envuelven todo el ambiente. La mujer, sobrecogida por la opresión, siente que da «un grito más poderoso que mi propia voz, tanto que yo misma me asusto» (p. 47). Pero ese grito ocurre en medio de una realidad de sueños, como le ocurre también a Silvia, y el personaje no sabe si en verdad es suyo o es el aullido de protesta de las cosas que la rodean:

- ¿no sería más bien el grito de las cosas que me quería romper a mí?-. ¿No lo oyen? Tengo hambre, mamá, Comprame zapatos y un traje nuevo para el baile, mamá. Llevame al cine, mamá. Gastás mucho, mujer. ¿Qué pagaste con este cheque, mujer? El dinero se evapora en tus manos despilfarradoras, mujer (p. 48).

El ambiente fragmentado de la mujer adquiere proporciones cósmicas cuando los sonidos que la atormentan hacen referencia a las masacres de Viet Nam, los horrores de la Revolución chilena y la multitud de asesinatos, suicidios e injusticias que acosan al ser humano. El personaje, que desea salir del mundo caótico en que vive, encuentra una liberación interior, pasiva. Se refugia en su «interior-vientre» (p. 48) hasta aniquilar su propia personalidad y quedar sepultada dentro de sí misma.

«Bajo pena de muerte» presenta un tema opuesto al discutido en el discurso anterior. La escritora presenta a la madre y esposa abnegada, que ante la problemática de la vida es capaz de convertirse en amazona benéfica. El discurso se lleva a cabo desde el punto de vista de un niño cuyo padre ha sido fusilado por problemas políticos. La madre, «hecha carne de dolor» (p. 65), se da a la trágica tarea de recobrar el cadáver de su esposo para darle cristiana sepultura. La búsqueda que aparece descrita 
como «un descenso al infierno» (p. 66) es una empresa sobrehumana para la mujer y el niño. Pero tal es la audacia y la transformación del personaje fememino, que el niño piensa azorado:

Ella, que se había confundido siempre con las cosas por su pequeñez, Lhabía crecido durante la noche, pues ahora él tenía que empinarse mucho para mirarla a los ojos? En aquellos momentos su silueta se recortaba con precisión en el aire de la mañana, y cuando hablaba, su voz era muy clara, aunque profundamente dolorosa; Pablo llegó a pensar que su voz de antes había permanecido nublada por los años como un cielo encapotado; sólo la tormenta de la noche se la había dejado limpia de nubarrones (p. 66).

La mujer, encontrando fuerzas dentro de sí y haciendo que su entereza ilumine el camino, llega hasta el bosque donde se encuentran abandonados los cuerpos de las infelices víctimas de la violencia política. Los soldados que montan guardia en el lugar aparecen deshumanizados y el niño los percibe fragmentados, desmenuzados en la oscuridad. El cuento culmina con la imposibilidad de la empresa cuando la mujer se entera que el rescate del cadáver significaría la pérdida de la vida del viejo sepulturero, quien, so pena de muerte, vela por la seguridad de los cuerpos de los fusilados. El personaje femenino de este cuento alcanza grandes proporciones literarias y humanas. Refleja un ser humano que rehúsa doblegarse ante las grandes tragedias y es capaz de enfrentarse a la injusticia.

«Alma-en-pena» ${ }^{13}$ presenta el mismo aire de irrealidad que aparece en los cuentos de Mujeres y agonías y en algunas narraciones de Polvo del camino. El ambiente en que se mueve el personaje femenino es también el diminuto universo del hogar. A diferencia de las otras narraciones, ésta acusa la presencia de un narratario. Mientras el esposo encuentra solaz en la lectura del periódico y los reportajes alarmantes de la precaria situación mundial, Nina, la esposa, se aburre ante una vida monótona y poco estimulante:

... porque mi vida aquí, ¿qué es?, pues una sucesión de días sin sentido, sólo el domingo cambia con la misa y la homilía, después, todo, bueno, ya sabés, Isidoro, todo es rutinario, aburrido, qqué se yo!

Vive una vida muy suya, muy metida dentro de ella misma, de la casa, los rutinarios quehaceres, y claro, con mi trabajo absorbente no le veo solución.

13 Véase nota 2. 
Aunque la mujer desea salir de la vida que la abruma dedicándose a servicios voluntarios, el lector se da cuenta de que ella ya ha logrado establecer una ruptura con lo normal y lo cotidiano y se ha refugiado en el reino de lo irreal. Aparece convencida de que en sueños se le ha aparecido el ánima de una joven asesinada y le ha revelado la identidad del asesino. El ánima no podrá encontrar reposo hasta que no se prenda al responsable de su muerte. El esposo teme que la mujer esté al borde de la locura, ya que tiene herencia de demencia. La propia madre fue víctima de un ataque de locura durante el cual le dio muerte al padre. Así expresa el esposo:

¿Hay algo de extraño que después ella también se vuelva loca? A veces, recordando el crimen, me dice con agonía que en los sueños de la noche, vos sabés, Isidoro, yo adivino que dentro de mí va cuajando algo en forma que no alcanzo a distinguir. Es como si todavía la distancia entre eso y yo fuera tal, que su imagen resulta imprecisa (p. 24).

El esposo, que tenía cierta desconfianza en la historia de su esposa al principio del cuento y que aún no comprende el escape emocional de la mujer, termina por creerle. Así encuentra necesario informar a las autoridades del crimen y manifestar que «eso de un ánima-en-pena es algo serio e impostergable» (p. 126).

Una realidad onírica y amenazante, aunque muy distinta a la de los cuentos anteriores, aparece en el mundo ficticio de Rita Creso, personaje central de "Los males venideros» ${ }^{14}$. La narración, que constituye una especie de «metacuento», presenta a una escritora enfrentándose por primera vez a una computadora procesadora de palabras. El personaje se maravilla de los avances tecnológicos de la época, pero medita sobre el hecho que hoy día «ya ni el pan ni la leche traen a las casas», pero una máquina electrónica sí se entrega a domicilio y se la deposita «en el escritorio como si fuera porcelana fina» (p. 221). Dicho comentario sugiere una queja sobre la deshumanización de la época de las máquinas.

La escritora recibe la computadora con grandes muestras de alegría:

Su entusiasmo no tuvo límites cuando supo que ya nunca más habría de emborronar cuadernos con su caligrafía de patas-de-cucaracha, porque todas las tramas de sus cuentos y novelas quedarían almacenadas en esa monumental memoria de la máquina de escribir (p. 222).

Aunque siente gran admiración por esa memoria mecánica todopoderosa,

${ }^{24}$ Véase nota 4 . Todas las citas de «Los males venideros» se tomarán de la versión apuntada en la nota 4. 
el personaje comienza a recibir sorpresas desagradables. Mediante monólogos interiores, el lector sabe que la escritora echa de menos el papel en que solía hacer sus garabatos y hasta el olor del grafito proveniente del lápiz que utilizaba. El proceso de alienación se hace aparente cuando la máquina aparece como un obstáculo en el proceso creador. Ella ve la pantalla como «un muro fantasmal que se alza entre mi creación y yo. Es como si lo que escribiera no fuera mío» (p. 223). Así, su misma creación se le hace gradualmente más ajena y desconocida. Mientras la máquina imprime lo escrito, la mente del personaje divaga y surgen ante el lector sus temores más recónditos, su miedo de vivir en una sociedad donde el crimen cunde por doquier. Se atormenta al pensar que tal vez ella se haya olvidado de ponerle cerrojo a la puerta de su casa. La computadora termina de imprimir el remate del cuento «Los males venideros», el cual es una materialización de los temores de la escritora. El trasfondo histórico de la creación fantasmal es fácilmente identificable porque se centra en crímenes recientemente cometidos en los Estados Unidos y la América Central:

Estos tiempos de tecnología, átomos explosivos, contaminación del aire, viajes espaciales, cemento y plástico, han abierto la bocaza del crimen por donde el progreso vomita una recua de delincuentes viciosos y desalmados: pesadilla de Atlanta entre 1979 y 1980 que dejó treinta y nueve niños muertos; masacre de unas 360 víctimas a manos de un tal Lucas a quien se ve en la pantalla del televisor con cara sonriente cada vez que muestra a las autoridades dónde sepultó los despojos; veinticinco cadáveres putrefactos que desenterraron en las playas de Galveston, en Texas... (p. 225).

La enumeración aterradora continúa mencionando a Charles Manson y recordando el atentado contra Edén Pastora, Comandante Cero de los rebeldes de Nicaragua. La máquina entonces termina prediciendo el final trágico de Rita Creso, la escritora, que ha dejado el llavero colgando de la puerta exterior de la casa y que está a punto de ser víctima de un criminal. Es interesante notar que en esta narración Vallbona recurre a uno de esos silencios en textos literarios que a veces no resultan elocuentes para el lector despistado: el nombre de Rita Creso es el anagrama de escritora.

Los cuentos de Rima de Vallbona examinados en este trabajo reflejan un mundo femenino lleno de ansiedades, frustraciones y a veces de neurosis. Con excepción de «Los males venideros», los entes que pueblan este mundo de imaginación son mujeres que, en general, octpan el lugar primario, tradicional asignado por la sociedad, y así se ven en una posición 
marginal en la vida. Este aspecto les presta un elemento universalizador a sus cuentos porque, aunque presentan una visión del mundo femenino desde una perspectiva interior, logran abarcar la vasta mayoría de las mujeres del mundo ${ }^{15}$. Sin embargo, los cuentos de Vallbona no son del todo pesimistas, a pesar de estar cargados de sentimientos de inseguridad. Verdaderamente parecen ser instrumentos positivos en el proceso de renovación del mundo femenino. En ellos surge un cuestionamiento filosófico del papel de la mujer en la sociedad contemporánea. Aunque su discurso tiene espíritu de denuncia, la escritora no predica ni sanciona. Su inquietud va implícita en el texto, en las vicisitudes de los personajes y en las situaciones que presenta.

${ }^{25}$ Elise Boulding, Women in the Twentieth Century World (New York: John Wiley \& Sons, 1979), p. 227. 